
and Aquatic Sciences

\title{
Paradox of otolith shape indices: routine but overestimated use
}

\begin{tabular}{|r|l|}
\hline Journal: & Canadian Journal of Fisheries and Aquatic Sciences \\
\hline Manuscript ID & cjfas-2020-0369.R1 \\
\hline Manuscript Type: & Article \\
\hline Author: & O9-Dec-2020 \\
\hline Complete List of Authors: & $\begin{array}{l}\text { Tuset, Víctor; Institut de Ciencies del Mar, Department of Renewable } \\
\text { Marine Resources } \\
\text { Otero-Ferrer, José Luis; Biostatech, Advice, Training and Innovation in } \\
\text { Biostatistics } \\
\text { Siliprandi, Carolina; Universidade de São Paulo } \\
\text { Manjabacas, Amalia; Institut de Ciencies del Mar, Department of } \\
\text { Renewable Marine Resources } \\
\text { Martí-Puig, Pere; Universitat de Vic, Grup de Processament del Senyal } \\
\text { Lombarte, Antoni; Institut Ciencies del Mar - CSIC/CMIMA }\end{array}$ \\
\hline Keyword: & otolith, shape, fish species, classification, methodological comparison \\
\hline $\begin{array}{r}\text { Is the invited manuscript for } \\
\text { consideration in a Special } \\
\text { Issue? : }\end{array}$ & \begin{tabular}{l} 
Not applicable (regular submission) \\
\hline
\end{tabular} \\
\hline
\end{tabular}

\section{SCHOLARONE ${ }^{\text {M }}$ Manuscripts}




\section{Paradox of otolith shape indices: routine but overestimated use}

2

3 Víctor Manuel Tuset, José Luis Otero-Ferrer, Carolina Siliprandi, Amàlia Manjabacas,

4 Pere Marti-Puig, and Antoni Lombarte

6 V.M. Tuset, A. Manjabacas, and A. Lombarte. Institut de Ciències del Mar (CSIC), Passeig Marítim 7 37-49, Barcelona 08003, Spain

8 J.L. Otero-Ferrer. Biostatech, Advice, Training and Innovation in Biostatistics (Ltd), Edificio

9 Emprendia, Campus Vida s/n, 15782 Santiago de Compostela, Spain

10 C. Siliprandi. Laboratório de Ictiofauna e Crescimento, Instituto Oceanográfico da Universidade de

11 São Paulo, Praça do Oceanográfico, 191, Butantã, 05508-120 São Paulo, Brasil

12 P. Marti-Puig. Grup de Processament del Senyal. University of Vic (UVIC-UCC), Vic, Spain 
19 Abstract: The identification of fish species using otolith shape has been common in many fields of the

20 marine science. Different analytical processes can be applied for the morphological discrimination, but

21 reviewing the literature we have found conceptual and statistical limitations in the use of shape indices

22 and wavelets (contour analysis), being specially worrying in the first case due to their widespread

23 routine use. In the present study, 42 species were classified using otolith shape indices and wavelets

24 and applying traditional and machine learning classifiers and performance measures (accuracy,

25 Cohen's kappa statistic, sensitivity and precision). Our results were conclusive, wavelets were a more

26 adequate option for the classification of species than shape indices, independently of classifiers and

27 performance measures considered. The artificial neural network and support vector machine provided

28 the highest values for all performance measures using wavelets. In all cases, the measures of sensitivity

29 and precision pointed out a higher confusion between some otolith patterns using shape indices.

30 Therefore, we strongly discourage the routine use of shape indices for the identification of species.

40 Keywords: otolith, shape, fish species, classification, methodological comparison 


\section{Introduction}

42 The otoliths or 'ear bones' of fishes are calcareous structures located in the inner ear of vertebrates,

43 and they act as sound detectors as well as organs of equilibrium (Popper and Coombs 1982; Popper

44 and Fay 2011; Schulz-Mirbach and Ladich 2016). Although there are three pairs (i.e., sagittae, lapilli

45 and asterisci), the sagittae otolith (henceforth referred to as otolith) shows a higher interspecific

46 variability in marine species (Gaemers 1984; Nolf 1985; Smale et al. 1995; Campana 2004; Tuset et

47 al. 2008; Lind and Chang 2012). Its shape was the focus of study in the first half of the $19^{\text {th }}$ century by

48 George Cuvier (Koken 1884; Campbell 1929), but it acquired a new analytical dimension with the

49 development of digital revolution in the 1980s. In that period, the term 'otolithometry', coined by

50 Gaertner (1982), was used to quantify interspecific and intraspecific variability using otolith biometry

51 and its relationship with physiological, genetic, ecological and evolutionary characteristics (Bird et al.

52 1986; Lombarte and Castellón 1991; Lombarte et al. 2010; Vignon and Morat 2010). The area and

53 perimeter were examined in addition to the initial linear measurements, such as length and width

54 (Gauldie 1988; Lombarte 1992; L’Abee-Lund 1988), allowing the calculation of classical shape

55 descriptors based on the measure combinations (e.g., ellipticity, circularity and rectangularity),

56 commonly known as 'shape indices'. These measurements became relevant and were additionally

57 applied with the contour analysis (Fourier descriptors) for the identification of fish stocks (Smith 1992;

58 Cadrin and Friedland 1999; Bergenius et al. 2005; Burke et al. 2008) and separately for taxonomic,

59 ecomorphological and ontogenetic studies (Tuset et al. 2003; Volpedo and Echeverría 2003; Zhuang et

60 al. 2014; Pavlov 2016; Lin and Al-Abdulkader 2019). In turn, shape indices have been used in

61 investigations of trophic (de Carvalho et al. 2019; Qamar et al. 2019; Assis et al. 2020) and

62 phylogenetic nature (Zhuang et al. 2014; Teimori et al. 2019). However, they have some analytical

63 problems that may disrupt the accuracy of the classifiers. First, most shape indices are strongly

64 intercorrelated, leading to multicollinearity problems. Although the application of principal component 
analysis (PCA) and redundancy elimination (e.g., stepwise procedure or VIF analysis) are plausible alternatives (Naes and Mevik 2001; Burke et al. 2008; Zhuang et al. 2014), many studies ignore this problem, which may overestimate the predictive power of their models (Mérigot et al. 2007; Gorini and Burrati 2017; Lin and Al-Abdulkader 2019). When PCA is performed, the first component may reach up to $99 \%$ of the total variance (Pavlov 2016), which is why the selection of more components would not avoid partial multicollinearity. Second, many automated image analyses turn the otoliths in relation to maximum Feret's length (Tuset et al. 2003; De la Cruz-Agüero et al. 2012; Zischke et al. 2016), which may distort the measures for uncommon shapes in fish taxa such as Beryciformes, Caproiformes, Gobiiformes, Gasterosteiformes, Pleuronectiformes, Tetraodontiformes and Zeiformes (Smale et al. 1995; Lombarte et al. 2006; Tuset et al. 2008).

The methods of contour analysis provide more complex knowledge on the otolith shape variability. Although elliptical Fourier analysis (EFA) is the most common method (Bird et al. 1986; Castonguay et al. 1991; Campana and Casselman 1993), it only gives a global approximation of outline variability since each harmonic coefficient by itself has no morphological meaning and cannot discriminate local singularities (Rohlf and Archie 1984; Parisi-Baradad et al. 2005; Reig-Bolaño et al. 2010). For that reason, new approaches such as wavelets, curvature scale space, bending energy, fractal dimension, short-time Fourier transform, mean distances, and geometric morphology have been developed (Monteiro et al. 2005; Parisi-Baradad et al. 2005, 2010; Piera et al. 2005; Youssef et al. 2016). Among them, multiscale wavelet analysis has been demonstrated to be an excellent method for underlining morphological singularities and their position along contour (Parisi-Baradad et al. 2005, 2010; Lombarte and Tuset 2015), becoming a powerful method to detect inter- and intraspecific differences (Sadighzadeh et al. 2014; Tuset et al. 2015, 2020; Lombarte et al. 2018). The AFORO database (http://aforo.cmima.csic.es/; Lombarte et al. 2006), the world's largest marine fish otolith database consisting of more than 2000 species and 7000 images, operates with this technique and has the option of attaching images for the online classification of species based on the $K$-nearest neighbours (KNN) 
90 learning algorithm (Parisi-Baradad et al. 2010). The conceptual development and mathematical

91 analysis of wavelets involved learning from the analysis of points (coefficients) (Sadighzadeh et al.

92 2012) to all-signal processing by means of principal component analysis demonstrating the real power

93 of this technique (Abaad et al. 2016; Tuset et al. 2016, 2018; Costa et al. 2018).

94 Instead of the extended opinion, we support the hypothesis that classical shape indices lose much

95 information about the real otolith shape, which is why they are not recommended for works related to

96 the identification of fish species. To clarify this specific question, this paper aims to (i) test the degree

97 of multicollinearity between shape indices and to select the most adequate for posterior analyses, (ii)

98 apply different parametric (linear discriminant analysis) and nonparametric algorithms ( $K$-nearest

99 neighbours, random forest, support vector machine and neuronal networks) to find the best solution for

100 each morphological method (shape indices versus wavelet), (iii) examine the use of performance

101 measures as a tool in the determination of the suitability of models, and (iv) conclude on the suitability

102 of shape indices for the identification of species.

\section{Material and methods}

105

\section{Otolith test sets}

107 Otolith images and morphological information were extracted from the AFORO database. The main reason for this selection was to have a good representation of the morphological patterns described by

109 Tuset et al. (2008) (Table 1, Fig. 1) and to avoid one specific fish assemblage affecting the final purpose

110 of the study. Thus, the set was composed of 420 otoliths of 42 fishes belonging to 37 families and 25

111 orders (Table 1). The total number of otoliths by species varied between 5 and 12, although the most

112 common was $>9$ otoliths by species. Total length ( $T L$ in $\mathrm{mm}$ ) was mostly the reference fish size, but in

113 some fish taxa, the preanal ( $P L$ in $\mathrm{mm}$; e.g., Trachyrincidae) and furcal length ( $F L$ in $\mathrm{mm}$; e.g., 
114 Scombridae) were used. In those specimens where the reference length was other (standard or furcal),

115 it was transformed using models provided by Fishbase (Froese and Pauly 2019) or by the relationship

116 between the otolith length and fish length given by Giménez et al. (2016). The set was characterized

117 by the presence of juveniles and adults, which is why the intraspecific morphological variability was

118 guaranteed.

\section{Shape indices}

121 The AFORO database provided morphometry data on otolith length ( $L$ in $\mathrm{mm})$, width $(W$ in mm), 122 area $\left(A\right.$ in $\left.\mathrm{mm}^{2}\right)$ and perimeter $(P$ in $\mathrm{mm})$ (Table S1, see Supplementary material). Estimating the shape 123 indices was initially necessary to remove the effect of the individual size of each specimen. For that, 124 all measurements were normalized taking into account the allometric relationships, otolith measure=

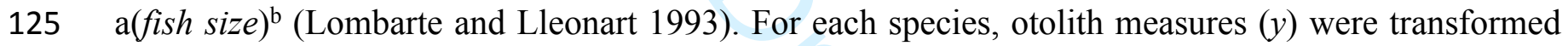
126 into $z$ according to $z=y\left(x_{0} x^{-1}\right)^{\mathrm{b}}$, where $x$ is the fish size of each individual, $x_{\mathrm{o}}$ is the mean fish size for 127 each species, and $b$ is the slope of the allometric relationship between fish size and each otolith 128 measure.

129 The shape indices estimated from the standardized morphometric data were as follows (Russ 1990;

130 Tuset et al. 2003; Volpedo and Echevarría 2003; Assis et al. 2020): aspect ratio $\left(A R=W L^{-1}\right)$, circularity

$131\left(C I R=P^{2} A^{-1}\right)$, edge complexity $\left(E C=P(2 \sqrt{ } \pi A)^{-1}\right)$, ellipticity $(E L L=(L-W) /(L+W)$, formfactor $(F F=$ $\left.132(4 \pi A) P^{-2}\right)$, rectangularity $\left(R E C=A(L W)^{-1}\right)$ and roundness $\left(R O=(4 A)\left(\pi L^{2}\right)^{-1}\right) \quad($ Table $\mathrm{S} 2$, see 133 Supplementary material). The aspect ratio expresses the tendency in the shape (circular or elongated).

134 Roundness and circularity provide information on the similarity of various features to a perfect circle, 135 taking a minimum value of 1 and $4 \pi(12.57)$, respectively. Edge complexity describes irregularities on 136 otolith edges. Ellipticity indicates whether the changes in the axes are proportional. Formfactor is a 137 means to estimate the surface area irregularity, taking values of 1.0 when it is a perfect circle and $<1.0$ 138 when it is irregular. Finally, rectangularity describes the variations of length and width with respect to 
139 the area, with 1.0 being a perfect square. Similar to other biological indices (e.g., functional indices;

140 Dumay et al. 2004), allometry was eliminated by standardizing the original otolith measurements by 141 computing the indices (Zischke et al. 2016: Tuset et al. 2018).

\section{Wavelets}

144 The wavelet transformed (WT) provides a $2^{\mathrm{n}}$ multiscale decomposition (Mallat 1991) based on

145 normalized equally spaced radii length. In particular, we considered the wavelet function at the $5^{\text {th }}$ 146 scale because several studies have demonstrated that this scale better describes the specific 147 characteristics of otolith contour (Parisi-Baradad et al. 2010; Sadighzadeh et al. 2012; Tuset et al. 2016, 148 2018, 2020: Lombarte et al. 2018). A total of 512 equidistant Polar coordinates for each otolith were 149 extracted using the rostrum (see otolith terminology in Tuset et al. 2008) as the origin. Wavelets were 150 directly obtained from the AFORO database (Fig. 2). A principal component analysis (PCA) based on 151 the variance-covariance matrix was performed to reduce the dimensionality of the 512 data points 152 obtained for each individual without a significant loss of information. Significant eigenvectors were 153 identified by plotting the percentage of total variation explained by the eigenvectors $v s$. the proportion 154 of variance expected under the 'broken-stick model' (Gauldie and Crampton 2002). Given that 155 interspecific differences might be attributed to allometry, linear correlations were tested between $\log _{10^{-}}$ $156 L$ and the principal components. The effect of otolith length was removed using the residuals of the 157 common slopes of the linear regressions of each component on otolith length, building a new PCA 158 matrix.

\section{Statistical methods}

161 A Spearman correlation $(\rho)$ was conducted to examine the pairwise association between shape 162 indices. When the correlation coefficients were $\geq 0.6$, they were considered problematic by collinearity 163 between them. For that, the variance inflation factor (VIF) was used to check the collinearity between 
164 the shape indices, where VIF scores greater than 10 were eliminated as predictors (Quinn and Keough

165 2002). This VIF factor was estimated with the vifstep function of the usdm package (Naimi et al. 2014)

166 for R (R Core Team 2020). To avoid the loss of information of some indices, a PCA analysis was also

167 performed with all indices. Only the first component was significant and explained $99.6 \%$ of the

168 variance (Fig. S1, see Supplementary material), which was why this option was discarded after 169 analyses.

170 Four classifiers were compared. a) Linear discriminant analysis (LDA) is the most common 171 parametric method used in the literature (Stransky et al. 2008a, b; Zhang et al. 2013; Teimori et al. 172 2019). b) $K$-nearest neighbour (KNN) determines the classification of objects finding the $k$ closest 173 neighbours of a query element inside the database by comparing one by one in the feature space and 174 with a distance metric defined in this space (Marti-Puig and Reig-Bolaños 2016); the advantage of $175 \mathrm{KNN}$ is its higher tolerance in the data structure (Hastie et al. 2009). c) Random forest (RF) involves 176 a nonlinear ensemble or forest of many tree classifiers in which class assignment occurs using an 177 average of the forest of trees (Breiman 2001; Jones and Checkley 2017). It balances errors in data sets 178 where classes are imbalanced and can train with a relatively small number of samples to obtain good 179 results. It is a very common method in the classification of species/stocks based on otolith 180 microchemistry (Mercier et al. 2011; Régnier et al. 2017). d) Support vector machine (SVM) with 181 linear kernel is a maximum margin classifier that maps the original feature space to higher dimensions.

182 It has the ability to deal with high-dimensional datasets and its flexibility in modelling diverse data 183 sources (Ben-Hur et al. 2008). It has been used for automatic fish ageing (Fablet et al. 2005; Bermejo 184 et al. 2007) and identification of species using shape and microchemistry (Castro 2007). e) Artificial 185 neural networks (ANNs) are systems based on a network architecture, where the smallest unit is the 186 neuron. Thus, the network is composed of three neuron layers: input layers groups: input layer 187 (morphological variables), hidden layers (nodules from $i=1 \ldots n$ ) and output layer (species). We used 188 a multi-layer perceptron (MLP) architecture and a back-propagation gradient algorithm to calibrate it 
189 (Youusef et al. 2016; Ciaburro and Venkateswaran 2017). The ANN has also been used in other otolith 190 applications, such as ageing (Roberston and Morison 1999; Moen et al. 2018) and microchemistry 191 (Hanson et al. 2004; Mercier et al. 2011).

192 The classifications were performed using the caret package in R (Kuhn 2008) for R. Leave-one-out 193 cross-validation (LOOCV) was the strategy selected; in this case, all observations are used for both 194 training and validation, where each one is being used once for validation. Thus, all observations are 195 tested against the rest, so we know how each particular element is classified. This strategy is 196 recommended by small datasets by species (Marti-Puig et al. 2015, 2020), as occurs in our dataset. The validation method was repeated 1000 times for each analysis. The models were built using scaled and centered predictor variables. The optimal hyperparameters of KNN $(k), \mathrm{RF}(\mathrm{mtry}), \mathrm{SVM}(\sigma$ and $\mathrm{C})$ and ANN (hidden units) were defined during preliminary tuning (Fig. S2, see Supplementary material). The additional R packages used for each model were MASS (Venables and Ripley 2002) of LDA, caret (Kuhn 2008) for KNN, randomForest (Liaw and Wiener 2002) for RF, kernlab (Karatzoglou et al. 2004) for SVM and RSNNS (Bergmeir and Benitez 2012) for ANN.

The performance of these models was evaluated and compared using several criteria: accuracy,

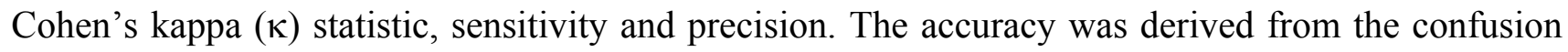
matrix following the following formulae: $(\mathrm{TP}+\mathrm{TN}) /(\mathrm{TP}+\mathrm{FP}+\mathrm{TN}+\mathrm{FN})$, where $\mathrm{TP}$ indicates otoliths correctly classified, TN denotes otoliths correctly non-assigned, FP reveals otoliths assigned to other species, and FN gives otoliths wrong classified by the model to other species. The kappa statistic estimates the improvement over chance of the percent corrected classification rates (Titus et al. 1984). The sensitivity establishes the proportion of otoliths correctly classified in relation to classified by the algorithm as true $(\mathrm{TP} / \mathrm{FN})$. The precision indicates the proportion of otoliths correctly classified by the model (TP/FP) (Altman and Bland 1994; Powers 2011). 


\section{Results}

215 The shape indices presented statistically significant non-zero correlations $(p<0.05)$, except for the 216 rectangularity with aspect ratio (Spearman's $\rho=-0.01)$ and ellipticity $(\rho=0.01)$ (Fig. 3). Only these

217 three indices showed correlations $<0.6$ with the remaining indices. The VIF analysis evidenced the 218 high collinearity between the shape indices indicating a multicollinearity effect (VIF $>10$; Table S3),

219 being the best option to avoid this problem the selection of rectangularity, ellipticity and formfactor 220 (VIF $<2$; Table S3, see Supplementary material). Therefore, only three indices (rectangularity, 221 ellipticity and formfactor) were used for the classifiers. In the wavelet analysis, the first 17 components 222 of the PCA analysis accounted for higher variance than expected by chance alone (96.4\%), reaching 223 the first three components $\sim 56 \%$ of the variance (Table S4, see Supplementary material).

224 The comparison of the accuracy and kappa index between classifiers and otolith analysis methods 225 (shape indices versus wavelet function at $5^{\text {th }}$ scale) demonstrated that a) ANN and RF presented lower 226 accuracy for the shape indices (accuracy and kappa indices $<70 \%$ ), b) the use of wavelets always

227 provided better results ( $>80 \%$ for both) than shape indices, and c) SVM was the best method for shape 228 indices $(79.6 \%$ of accuracy and Cohen's $\kappa$ indicates that a classification efficiency of $79.3 \%$ better than 229 would have occurred by chance alone) and for wavelets (96.7\% and 96.6, respectively), although ANN 230 also gave excellent results for wavelets (96.7\%) (Table 2). However, the analysis of the distribution of 231 the value of sensitivity and precision for each species did not confirm the efficiency described, 232 especially for the shape indices, there were species with values sensitivity $<10 \%$ (Fig. $4 a$ ) and precision $233<50 \%$ (Fig. $4 b$ ). In particular, ANN showed problems of reliability in $\sim 50 \%$ of species (Table S5), 234 whereas KNN, LDA and RF were $\sim 36 \%$ (Tables S6-S8, see Supplementary material) and SVM $\sim 36 \%$ 235 (Table S9, see Supplementary material). The efficiency problem of these classifiers with otolith shapes 236 not excessively rare is highlighted. In contrast, the identification of species using the wavelet function 
237 only induced some mistakes for RF ( $14 \%$; Table S8, see Supplementary material) and one low 238 sensitivity in S. kaupii for KNN (Table S6, see Supplementary material). The ANN, LDA and SVM 239 classifiers maintained high values for the performance measures (Tables S5, S7 and S9, respectively; 240 see Supplementary material), but their distributions were less efficient when using LDA (Figs. 4a and $241 b)$.

\section{Discussion}

The present study compared the efficiency in the identification of fish species using classical otolith shape indices and contour analysis, represented by the wavelet transformed function. Our findings were conclusive. a) Wavelet analysis is a better method than shape indices for shape analysis, independent of the type of classifier. b) The correct analysis of wavelets is essential for obtaining satisfactory results. The wavelet transform is a signal processing technique for why few points (or coefficients) cannot rightly define the otolith shape, and a drastic reduction, as occurs in the shapeR package, is advised against (Libungan and Pálsson 2015). A clear example of this effect can be illustrated using the study performed by Lin and Al-Abdulkader (2019), who compared otolithometry, shape indices and wavelets

253 for the identification of species and families. The wavelet function (only represented by 26 coefficients) obtained the worst results in almost all cases. c) The accuracy cannot be the unique criterion for the justification and selection of analytical variables and classifiers. We strongly recommend that any study should not accept as valid an unbalanced model where the prediction of one or some species may be

257 low, despite the high accuracy of the whole model. Therefore, it is necessary to reinforce the 258 complementary use of performance measures. Finally, d) the accuracy of models depends not only on 259 the number of species analysed but also on the variability of shapes and the ability of the method to 260 discriminate them. 


\section{Limitations of shape indices}

263 Our findings demonstrated that shape indices are not the good methodology assuring the correct 264 classification of all fish species. This is mainly because the ideal geometric form of the shape indices 265 does not necessarily imply the real description of the object. Thus, otoliths clearly distinctive from the naked eye can have similar values of shape indices, as occurred between Arctozenus risso (otolith with

267 trapezoidal shape) and Engraulis encrasicolus (otolith with elliptic shape) (Fig. 5a, Table S2, see Supplementary material). However, the strong multicollinearity between the indices limited the number of variables in analytical procedures, thus avoiding a better accuracy of models. Considering the LDA classifier, a low sensitivity occurred in $45.2 \%$ of species, whereas Lin and Al-Abdulkader (2019) provided $37.5 \%$ sensitivity using all shape indices. This means that multicollinearity would overfit the accuracy and performance measures, but in otoliths with less heterogeneous morphologies, uncommon shapes, such as trilobulated (Macroramphosus scolopax), pentalobulated (Zeus faber), hour-glass (Capros aper), sagittiform (Gadella maraldi), or tall (Argyropelecus hemigymnus), were correctly classified, despite presenting higher intraspecific variability. In contrast, more common morphologies, such as elliptic (Alosa fallax, Engraulis encrasicolus, Lithognathus mormyrus and Vinciguerria nimbaria), rectangular (Chelon aurata), cuneiform (Labrus mereula), or oval (Mullus surmmuletus), revealed a lower sensitivity and precision. Nevertheless, the low number of shape indices and the number of specimens considered also influence in the model accuracy.

The otolith shape depends on the ecological, evolutionary and phylogenetic characteristics of species (Škeljo and Ferri 2012; Zhuang et al. 2014: Tuset et al. 2015, 2016; Mille et al. 2016; Lombarte et al. 2018; Teimori et al. 2019), which are not always differentiated by the shape indices. For instance, otolith shape changes can be more or less prominent and localize in sections or the whole contour 
286 shifts are small, the shape indices may remain constant, which occurs, for example, in

287 Synaphobranchus kaupii (Fig. 5b; present study) and other fish species (Tuset et al. 2003, 2008; Adelir-

288 Alves et al. 2018; Avigliano et al. 2018). Even if the shifts are noticeable, the interspecific differences

289 may not significantly increase the model confusion. In addition, models with few numerous and

290 heterogeneous variables conditioned the discriminatory ability of species. All these particulars arise in

291 the present study, where only three shape indices were included in the models presenting two of them

292 (rectangularity and formfactor) a low dispersion, why the combination of these variables was

293 insufficient for building a model with a high sensitivity and precision. Given the problems that may

294 appear, why do the shape indices provide good results in some studies? Usually, these studies compare

295 few species with clear variations in otolith shapes. For that reason, to infer the idea that shape indices

296 can be used to identify species from the comparison of the number of species reduced, usually

297 belonging to the same family, is simply a fallacy. Any automated taxon identification (ATI) using

298 bigdata (e.g., AFORO database) can never apply classical shape indices for the identification of

299 species, and they are only useful tool in specific cases. Although alternative shape indices have been

300 proposed with success (Tuset et al. 2006), this line of research has not been fully explored. Therefore,

301 it seems more logical to continue working with contour analysis, particularly with the wavelet function

302 (Sadighzadeh et al. 2012), which provides sufficient accuracy considering the magnitude and

303 limitations of the AFORO database. Moreover, the possibility of delimiting specific sections of otoliths

304 opens very interesting analytical options (Tuset et al. 2015).

305

\section{Learning algorithms}

307 The major limitation of classical classifiers in the identification of species and stocks is the violation

308 of normality. It can be a serious problem when it is caused by outliers (Zuur et al. 2009), which results

309 in intra- and interspecific variability. Although parametric methods can be more powerful, machine-

310 algorithm methods are a valid alternative, providing excellent results in the identification of species 
311 (Parisi-Baradad et al. 2010; Zischke et al. 2016; Youssef et al. 2016) and stocks (Smoliński et al. 2020).

312 In this context, the present study is the first comparing different models using the shape indices and

313 wavelet function. In the case particular of shape indices, the SVM algorithm achieved the highest

314 accuracy, but KNN provided the best results for the performance measures. Given that the increment

315 of accuracy in both models is relatively small $(\sim 6 \%)$, it seems more reasonable to consider the KNN

316 model as the best-performing algorithm. In this context, it was highlighted that both ANN and RF

317 attained the worst accuracies, which suggests an effect of a low number of variables (three) considered.

318 In contrast, the use of wavelets increased noticeably $(\sim 15-37 \%)$ the success of classification and

319 performance measures, with SVM and ANN being the best options. Nevertheless, all models provided

320 good accuracies and have been used with successful KNN (Parisi-Baradad et al. 2010), LDA and SVM

321 (Zischke et al. 2016), and ANN (Youssef et al. 2016). However, SVM and ANN are complex processes

322 that significantly increase the lead time of forecasting. This leads to problems that are more pragmatic

323 than mathematical: speed up or be accurate. When the study is limited in the number of species and

324 numerous in specimens, the processing time of complex learning algorithms is assumable. However,

325 when scientists using online classification are looking for a faster solution, KNN continues to be an

326 acceptable option. In any case, these findings stress the importance of the model choice and the

327 characteristics of the otolith data set on the analysis. For instance, SVM seems to be the algorithm more

328 useful for the identification of stocks using the otolith shape (Smoliński et al. 2020), and RF

329 outperforms ANN using otolith microchemistry (Mercier et al. 2011). In contrast, DNN (deep neural

330 network, a model of ANN using a large number of hidden layers) would have considerable potential

331 for ageing (Moen et al. 2018; Moore et al. 2019). Consequently, the generalized application of more

332 complex learning algorithms in all fields of otoliths seems unstoppable, including the identification of

333 species from bigdata and hence the parametric models living on borrowed time.

\section{Conclusions}


336 The choice of the criteria at different levels of mathematical procedures makes the standardization 337 of a methodology in this field complex, including issues such as how to solve the number of 338 components in the PCA (Jolliffe 2002) and the effects of small rotations and variations in the starting 339 point of contour analysis on the model efficiency (Marti-Puig and Reig-Bolaño 2016; Marti-Puig et al. 340 2020). It is likely that the future includes deep learning classifiers based on multiple images as occurs

341 in ageing (Moen et al. 2018), which could be positive when considering the sulcus acusticus and

342 training and test sets. However, this requires a large amount of information that is not available and

343 likely cannot be never available for many rare or few common species, but that is the purpose of the

344 AFORO database. In addition, our target is provided as the best method and model for the classification

345 of species for researchers in different fields, and KNN is currently a faster solution but revisable in the

346 future. We do not reject the use of the classical shape indices, but whether the assertation on their

347 goodness in relation to the contour analysis, especially when the multicollinearity effect is not

348 considered, and few species are being compared (Lord et al. 2012). Thus, their routine use loses its

349 essence and usefulness, showing their visibility in models with performance measures. Each year,

350 hundreds of scientists extract thousands of otoliths for different purposes, creating large amounts of

351 data and images. This big data information requires a deeper computation and accuracy than classical

352 shape indices can provide.

\section{Acknowledgments}

355 This study was supported by the Catalan Government project PESCAT (FEM/DARP/1256/2018)

356 and the images were obtained from AFORO project, and S. Campana, C. Asssis, C.H. Lin and C.W.

357 Chang publications. The English was revised by the agency AJE. The authors wish also to thank two 358 anonymous referees for their helpful suggestions. 
360

361

362

363

364

365

366

367

368

369

370

371

372

373

374

375

376

377

378

379

380

381

382

383

384

385

386

387

\section{References}

Abaad, M., Tuset, V.M., Montero, D., Lombarte, A., Otero-Ferrer, J.L., and Haroun, R. 2016. Phenotypic plasticity in wild marine fishes associated with fish-cage aquaculture. Hydrobiologia 765: 343-358. doi: 10.1007/s10750-015-2428-5.

Adelir-Alves, J., Daros, F.A.L.M., Spach, H.L., Soeth, M., and Correia, A.T. 2018. Otoliths as a tool to study reef fish population structure from coastal islands of South Brazil. Mar. Biol. Res. 14: 3973-988. doi: $10.1080 / 17451000.2019 .1572194$.

Altman, D.G., and Bland, J.M. 1994. Statistics notes: diagnostic tests 1: sensitivity and specificity. BMJ 308:1552. doi: 10.1136/bmj.308.6943.1552.

Assis, I.O., da Silva, V.E.L., Souto-Vieira, D., Lozano, A.P, Volpedo, A.V., and Fabré, N.N. 2020. Ecomorphological patterns in otoliths of tropical fishes: assessing trophic groups and depth strata preference by shape. Environ. Biol. Fish. 103: 349-361. doi: 10.1007/s10641-020-00961-0.

Avigliano, E., Rolón, M.E., Rosso, J.J., Mabragaña, E., and Volpedo, A. 2018. Using otolith morphometry for the identification of three sympatric and morphologically similar species of Astyanax from the Atlantic Rain Forest (Argentina). Environ. Biol. Fish. 101: 1319-1328. doi: 10.1007/s10641-018-0779-2.

Ben-Hur, A., Ong, C.S., Sonnenburg, S., Schölkopf, B., and Rätsch, G. 2008. Support vector machines and kernels for computational biology. PLoS Comput. Biol. 4: e1000173. doi: 10.1371/journal.pcbi.1000173.

Bergenius, M.A.J., Begg, G.A., and Mapstone, B.D. 2006. The use of otolith morphology to indicate the stock structure of common coral trout (Plectropomus leopardus) on the Great Barrier Reef, Australia. Fish. Bull. 104: $498-511$.

Bergmeir, C., and Benitez, J.M. 2012. Neural networks in R using the Stuttgart neural network simulator: RSNNS. J. Stat. Soft. 46: 1-26. doi: 10.18637/jss.v046.i07.

Bermejo, S., Monegal, B., and Cabestany, J. 2007. Fish age categorization from otolith images using multi-class support vector machines. Fish. Res. 84: 247-253. doi: 10.1016/j.fishres.2006.11.021.

Biolé, F.G., Thompson, G.A., Vargas, C.V., Leisen, M., Barra, F., Volpedo, A., et al. 2019. Fish stocks of Urophycis brasiliensis revealed by otolith fingerprint and shape in the Southwestern Atlantic Ocean. Estuar. Coast. Shelf Sci. 229:106406. doi: 10.1016/j.ecss.2019.106406.

Bird, J.L., Eppler, D.T., and Checkley, D.M. Jr. 1986. Comparison of herring otoliths using Fourier series shape analysis. Can. J. Fish. Aquat. Sci. 43: 1228-1234. doi: 10.1139/f86-152.

Breiman, L. 2001. Random Forests. Mach. Learn. 45: 5-32. doi: 10.1023/A:1010933404324. 
388

389

390

391

392

393

394

395

396

397

398

399

400

401

402

403

404

405

406

407

408

409

410

411

412

413

414

415

416

Burke, N., Brophy, D., and King, P.A. 2008. Shape analysis of otolith annuli in Atlantic herring (Clupea harengus); a new method for tracking fish populations. Fish. Res. 91: 133-143. doi: 10.1093/icesjms/fsn177.

Cadrin, S.X., and Friedland, K.D. 1999. The utility of image-processing techniques for morphometric analysis and stock identification. Fish Res. 43: 129-139. doi: 10.1016/s0165-7836(99)00070-3.

Campana, S.E. 2004. Photographic atlas of fish otoliths of the Northwest Atlantic Ocean. Can. Spec. Publ. Fish. Aquat. Sci. 133: 1-284. doi:10.1139/9780660191089.

Campana, S.E., and Casselman, J.M. 1993. Stock discrimination using otolith shape analysis. Can J. Fish. Aquat Sci. 50: 1062-1083. doi: 10.1139/f93-123.

Campbell, R.B. 1929. Fish otoliths, their occurrence and value as stratigraphic markers. J. Paleontol. 3: 254-279. https://www.jstor.org/stable/1298029.

Castro, B.G. 2007. Element composition of sardine (Sardina pilchardus) otoliths along the Atlantic Coast of the Iberian Peninsula. ICES J. Mar. Sci. 64: 512-518. doi: 10.1093/icesjms/fsm017.

Castonguay, M., Simard, P., and Gagnon, P. 1991. Usefulness of Fourier analysis of otolith shape for Atlantic mackerel (Scomber scombrus) stock discrimination. Can. J. Fish. Aquat. Sci. 48: 296-302. doi: 10.1139/f91-041.

Ciaburro, G., and Venkateswaran, B. 2017. Neural networks with R: smart models using CNN, RNN, deep learning, and artificial intelligence principles. Packt Publishing Ltd, Birmingham.

Costa, R.M.R. da, Fabré, N.N., Amadio, S.A., and Tuset, V.M. 2018. Plasticity in the shape and growth pattern of asteriscus otolith of black prochilodus Prochilodus nigricans (Teleostei: Characiformes: Prochilodontidae) freshwater Neotropical migratory fish. Neotropical Ichthyol. 16: e180051. doi: 10.1590/1982-0224-20180051.

de Carvalho, B.M., Spach, H.L., Vaz-Dos-Santos, A.M., and Volpedo, A. 2019. Otolith shape index: is it a tool for trophic ecology studies? J. Mar. Biol. Assoc. UK 99: 1765-1682. doi: 10.1017/S0025315419000729.

De la Cruz-Agüero, J., García-Rodríguez, F.J., De la Cruz-Agüero, G., and Díaz-Murillo, B.P. 2012. Identification of gerreid species (Actinopterygii: Perciformes: Gerreidae) from the pacific coast of Mexico based on sagittal otolith morphology analysis. Acta Ichthyol. Pisc. 42: 297-306. doi: 10.3750/AIP2012.42.4.03.

Dumay, O., Tari, P.S., Tomasini, J.A., and Mouillot, D. 2004. Functional groups of lagoon 396 fish species in Languedoc Roussillon, Southern France. J. Fish Biol. 64: 970-983. doi: 10.1111/j.1095-8649.2004.00365.x.

Fablet, R., and Josse, N.L. 2005. Automated fish age estimation from otolith images using statistical learning. Fish. Res. 72: 279-290. doi: 10.1016/j.fishres.2004.10.008.

Froese, R., and Paul, D. 2019. FishBase. World Wide Web electronic publication. www.fishbase.org, version (12/2019). 
Gaertner, D. 1982. Analyse biometrique de Solea lascaris (Risso, 1810) en Baie de Douarnenez (Finisterre). Cybium 6: 15-

418 33.

Gaemers, P.A.M. 1984. Taxonomic position of Cichlidae (Pisces, Perciformes) as demonstrated by the morphology of their otoliths. Neth. J. Zool. 34: 566-595. doi: 10.1163/002829684X00290.

Gauldie, R.W. 1988. Function, form and time-keeping properties of fish otoliths. Comp. Biochem. Physiol. 91: 395-402. doi: 10.1016/0300-9629(88)90436-7.

Gauldie, R.W., and Crampton, J.S. 2002. An eco-morphological explanation of individual variability in the shape of the 424 fish otolith: comparison of the otolith of Hoplostethus atlanticus with other species by depth. J. Fish Biol. 60: 1204-1221. doi: 10.1006/jfbi.2002.1938.

Giménez, J., Manjabacas, A., Tuset, V.M., and Lombarte, A. 2016. Relationships between otolith and fish size from Mediterranean and North-eastern Atlantic species to be used in predator-prey studies. J. Fish Biol. 89: 2195-2202. doi: $10.1111 / \mathrm{jfb} .13115$.

Gorini, F., and Burrati, C. 2017. Discriminating between the hakes Merluccius hubbsi and M. australis on the basis of their otolith morphometrics. Acad. J. Sci. Res. 4: 345-354. doi: 10.15413/ajsr.2016.0607.

Hanson, P.J., Christopher, C.K., and Zdanowicz, V.S. 2004. Elemental composition of otoliths used to trace estuarine

Jolliffe, I.T. 2002. Principal Component Analysis. Springer Verlag, New York. doi: 10.1007/b98835.

Jones, W.A., and Checkley, D.M. Jr. 2017. Classification of otoliths of fishes common in the Santa Barbara Basin based on morphology and chemical composition. Can. J. Fish. Aquat. Sci. 74: 1195-1207. doi: 10.1139/cjfas-2015-0566

Karatzoglou, A., Smola, A., Hornik, K., and Zeileis, A. 2004. Kernlab - An S4 package for kernel methods in R. J. Stat.

$$
\text { Soft. 11: 1-20. doi: 10.18637/jss.v011.i09. }
$$

Koken, E. 1884. Ueber Fisch-Otolithen, insbesondere über diejenigen der norddeutschen Oligocän-Ablagerungen. Z. Dt.

441 Kuhn, M. 2008. Building predictive models in R using the caret package. J. Stat. Soft. 28: 1-26. doi: 10.18637/jss.v028.i05.

442 L'AbeéLe-Lund, J.H. 1988. Otolith shape discriminates between juvenile Atlantic salmon, Salmo salar L., and brown trout 443 Salmo trutta L. J. Fish Biol. 33: 899-903. doi: 10.1111/j.1095-8649.1988.tb05538.x.

444 Liaw, A., and Wiener, M. 2002. Classification and regression by randomForest. R News 2: 18-22. 
445 Libungan, L.A., and Pálsson, S. 2015. ShapeR: an R package to study otolith shape variation among fish populations. PLoS 446 ONE 10: e0121102. doi: 10.1371/journal.pone.0121102.

447 Lin, Y-J., and Al-Abdulkader, K. 2019. Identification of fish families and species from the western Arabian Gulf by otolith 448 shape analysis and factors affecting the identification process. Mar. Freshw. Res. 70: 1818-1827.doi: 10.1071/MF18282.

450

Lin, C.H., and Chang, C.W. 2012. Otolith Atlas of Taiwan fishes. National Museum of Marine Biology and Aquarium, 451 Taiwan.

452

Lombarte, A. 1992. Changes in otolith area: sensory area ratio with body size and depth. Environ. Biol. Fish. 33: 405-410. doi: 10.1007/BF00010955.

Lombarte, A., and Castellón, A. 1991. Interspecific and intraspecific otolith variability in the genus Merluccius as determined by image analysis. Can. J. Zool. 69: 2442-2449. doi:10.1139/z91-343.

Lombarte, A., and Lleonart, J. 1993. Otolith size changes related with body growth, habitat depth and temperature. Environ. Biol. Fish. 37: 297-306. doi: 10.1007/BF00004637.

Lombarte, A., and Tuset, V.M. 2015. Morfometria de otólitos. In Métodos de estudo com otólitos: princípios e aplicações. CAFP-BA-PIESCI. pp. 269-302.

Lombarte, A., Chic, Ò., Parisi-Baradad, V., Olivella, R., Piera, J., and García-Ladona, E. 2006. A web-based environment from shape analysis of fish otoliths. The AFORO database. Sci. Mar. 70: 147-152. doi: 10.3989/scimar.2006.70n1147.

Lombarte, A., Palmer, M., Matallanas, J., Gómez-Zurita, J., and Morales-Nin, B. 2010. Ecomorphological trends and phylogenetic inertia of otolith sagittae in Nototheniidae. Environ. Biol. Fish. 89: 607-618. doi: 10.1007/s10641-0109673-2.

Lombarte, A., Miletić, M., Kovačić, M., Otero-Ferrer, J.L., and Tuset, V.M. 2018. Identifying sagittal otoliths of

Lord, C., Morat, F., Lecomte-Finiger, R., and Keith, P. 2012. Otolith shape analysis for three Sicyopterus (Teleostei: 10.1007/s10641-011-9907-y.

472 Marti-Puig P., and Reig-Bolano R. 2016. A rotation-invariant feature space according to environmental applications needs 
474

475

476

477

478

479

480

481

482

483

484

485

486

487

488

489

490

491

492

493

494

495

496

497

498

499

500

501

502

Marti-Puig P., Manjabacas A., and Lombarte, A. 2020. Fourier-based contour descriptors to relax positional standardization of the otolith images in AFORO queries. Sci. Mar. 84: 27-37. doi: 10.3989/scimar.04961.15a .

Marti-Puig P., Danés J., Manjabacas A., and Lombarte, A. 2015. New parameterization method for 3D otolith surface images. Mar. Freshw. Res. 67: 1059-1071. doi: 10.1071/MF15069.

Mercier, L., Darnaude, A.M., Bruguier, O., Vasconcelos, R.P., Cabral, H.N., Costa, M.J., and et al. 2011. Selecting statistical models and variable combinations for optimal classification using otolith microchemistry. Ecol. Appl. 21: 1352-1364. doi:10.1890/09-1887.1.

Mérigot, B., Letourneur, Y., and Lecomte-Finiger, R. 2007. Characterization of local populations of the common sole Solea solea (Pisces, Soleidae) in the NW Mediterranean through otolith morphometrics and shape analysis. Mar. Biol. 151: 997-1008. doi: 10.1007/s00227-006-0549-0.

Mille, T., Mahe, K., Cachera, M., Villanueva, M.C., De Pontual, H., and Ernande, B. 2016. Diet is correlated with otolith shape in marine fish. Mar. Ecol. Prog. Ser. 555: 167-184. doi: 10.3354/meps11784.

Moen, E., Handegard, N.O., Allken, V., Albert, O.T., Harbitz, A., and Malde, K. 2018. Automatic interpretation of otoliths using deep learning. PLoS One 13: e0204713. doi: 10.1371/journal.pone.0204713.

Monteiro, L.R., Di Benedetto, A.P.M., Guillermo, L.H., and Rivera, L.A. 2005. Allometric changes and shape differentiation of sagitta otoliths in sciaenid fishes. Fish. Res. 74: 288-299. doi: 10.1016/j.fishres.2005.03.002.

Moore, B.R., Maclaren, J., Peat, C., Anjomrouz, M., Horn, P.L., and Hoyle, S. 2019. Feasibility of automating otolith ageing using CT scanning and machine learning. New Zealand Fisheries Assessment Report 2019/58, Wellington.

Næs, T., and Mevik, B.H. 2001. Understanding the collinearity problem in regression and discriminant analysis. J. Chemom. 15: 413-426. doi: 10.1002/cem.676.

Naimi, B., Hamm, N.A.S., Groen, T. A., Skidmore, A.K., and Toxopeus A.G. 2014. Where is positional uncertainty a problem for species distribution modelling. Ecography 37: 191-203. doi: 10.1111/j.1600-0587.2013.00205.x.

Nolf, D. 1985. Otolithi piscium. In Handbook of Paleoichthyology. Gustav Fischer Verlag.

Parisi-Baradad, V., Lombarte, A., García-Ladona, E., Cabestany, J., Piera, J., and Chic, O. 2005. Otolith shape contour analysis using affine transformation invariant wavelet transforms and curvature scale space representation. Mar. Freshw. Res. 56: 795-804. doi: 10.1071/MF04162.

Parisi-Baradad, V., Manjabacas, A., Lombarte, A., Olivella, R., Chic, Ò., Piera, J. et al. 2010. Automated Taxon Identification of Teleost fishes using an otolith online database-AFORO. Fish. Res. 105: 13-20. doi: 10.1016/j.fishres.2010.02.005 
503 Pavlov, D.A. 2016. Differentiation of three species of the genus Upeneus (Mullidae) based on otolith shape analysis. J. $504 \quad$ Ichthyol. 56: 37-51. doi: 10.1134/S0032945216010094.

505 Piera, J., Parisi-Baradad, V., García-Ladona, E., Lombarte, A., Recasens, L., and Cabestany, J. 2005. Otolith shape feature 506 extraction oriented to automatic classification with open distributed data. J. Mar. Freshw. Res. 56: 805-814. doi: $507 \quad 10.1071 /$ MF04163.

508 Popper, A.N., and Coombs, S. 1982. The morphology and evolution of the ear in Actinopterygian fishes. Am. Zool. 22: 509 311-328. doi: 10.1016/j.heares.2009.12.023.

510 Popper, A.N., and Fay, R.R. 2011. Rethinking sound detection by fishes. Hear. Res. 273: 25-36. doi: $511 \quad$ 10.1016/j.heares.2009.12.023.

512

513

514

515

516

517

518

519

520

521

522

523

524

525

526

527

528

529

530

Powers, D.M.E. 2011. Evaluation: from precision, recall and f-measure to roc, informedness, markedness and correlation. J. Mach. Learn. Technol. 2: 37-63.

Qamar, N., and Panhwar, S.K. 2019. Otolith dimensions versus fish lengths estimated for five carangids (Pisces) in Pakistan. Pakistan J. Zool. 51: 1963-1965. doi: 10.17582/journal.pjz/2019.51.5.sc2.

Quinn, G.O., and Keough, M.K. 2002. Experimental design and data analysis for biologists. Cambridge University Press, UK.

R Core Team. 2020. R: A language and environment for statistical computing. Vienna, Austria.

Reig-Bolaño, R., Marti-Puig, P., Rodriguez, S., Bajo, J., Parisi-Baradad, V., and Lombarte, A. 2010. Otoliths identifiers using image contours EFD. In Distributed Computing and Artificial Intelligence. Advances in Intelligent and Soft Computing. Edited by A.P. de Leon F. de Carvalho, S. Rodríguez-González, J.F. De Paz Santana, and J.M.C. Rodríguez. Adv. Intell. Soft Comput. 79: 9-16. doi:10. 1007/978-3-642-14883-5_2.

Régnier, T., Augley, J., Devalla, S., Robinson, C.D., Wright, P.J., and Neat, F.C. 2017. Otolith chemistry reveals seamount fidelity in a deepwater fish. Deep Sea Res. 121: 183-189. doi: 10.1016/j.dsr.2017.01.010.

Robertson, S.G., and Morison, A.K. 1999. A trial of artificial neural networks for automatically estimating the age of fish. Mar. Freshw. Res. 50: 73-82. doi: 10.1071/MF98039.

Rohlf, F.J., and Archie, J.W. 1984. A comparison of Fourier methods for the description of wing shape in mosquitoes (Diptera: Culicidae). Syst. Biol. 33: 302-317. doi: 10.2307/2413076.

Russ, J.C. 1990. Computer-assisted microscopy: the measurement and analysis of images. Plenum Press, New York. doi: 10.1007/978-1-4613-0563-7. 
531 Sadighzadeh, Z., Tuset, V.M., Valinassab, T., Dadpour, M.R., Otero-Ferrer, J.L., and Lombarte, A. 2012. Comparison of 532 different otolith shape descriptors and morphometrics in the identification of closely related species of Lutjanus spp.

533 from the Persian Gulf. Mar. Biol. Res. 8: 802-814. doi: 10.1080/17451000.2012.692163.

534 Sadighzadeh, Z., Otero-Ferrer, J.L., Lombarte, A., Fatemi, M.R., and Tuset, V.M. 2014. An approach to unraveling the 535 coexistence of snappers (Lutjanidae) using otolith morphology. Sci. Mar. 78: 353-362. doi: 10.3989/scimar.03982.16C.

536 Schulz-Mirbach, T., and Ladich, F. 2016. Diversity of inner ears in fishes: possible contribution towards hearing 537 improvements and evolutionary considerations. In Fish Hearing and Bioacoustics: an anthology in honor of Arthur N. 538 Popper and Richard R. Fay. Springer International Publishing AG. pp. 343-394. doi: 10.1007/978-3-319-21059-9_16.

539 Skeljo, F., and Ferri, J. 2012. The use of otolith shape and morphometry for identification and size-estimation of five wrasse 540 species in predator-prey studies. J. Appl. Ichthyol. 28: 524-530. doi: 10.1111/j.1439-0426. 2011.01925.x.

541 Smale, M. J., Watsony, G. and Hecht, T. 1995. Otolith atlas of Southern African marine fishes, monograph 1. J.L.B. Smith 542 Institute of Ichthyological Research, Grahamstown. doi: 10.5962/bhl.title.141860.

543 Smith, M.K. 1992. Regional differences in otolith morphology of the deep slope red snapper Etelis carbunculus. Can. J.

$544 \quad$ Fish. Aquat. Sci. 49: 795-804. doi: 10.1139/f92-090.

545 Smoliński, S., Schade, F.M., and Berg, F. 2019. Assessing the performance of statistical classifiers to discriminate fish 546 stocks using Fourier analysis of otolith shape. Can. J. Fish. Aquat. Sci. 77: 674-683. doi: 10.1139/cjfas-2019-0251.

547 Stransky, C., Baumann, H., Fevolden, S., Harbitz, A., Høie, H., Nedreaas, K.H., et al. 2008a. Separation of Norwegian 548 coastal cod and Northeast Arctic cod by outer otolith shape analysis. Fish. Res. 90: 26-35. doi: $549 \quad$ 10.1016/j.fishres.2007.09.009.

550 Stransky, C., Murta, A. G., Schlickeisen, J., and Zimmermann, C. 2008b. Otolith shape analysis as a tool for stock 551 separation of horse mackerel (Trachurus trachurus) in the Northeast Atlantic and Mediterranean. Fish. Res. 89: 159166. doi:10.1016/j.fishres.2007.09.017.

Teimori, A., Khajooei, A., Motamedi, M., and Hesni, M.A. 2019. Characteristics of sagittae morphology in sixteen marine fish species collected from the Persian Gulf: demonstration of the phylogenetic influence on otolith shape. Reg. Stud. Mar. Sci. 29: 100661. doi: 10.1016/j.rsma.2019.100661. ecological applications. Am. Midl. Nat. 111: 1-7. doi: 10.2307/2425535.

558 Tuset, V.M., Rosin, P. L., and Lombarte, A. 2006. Sagittal otolith shape used in the identification of fishes of the 559 genus Serranus. Fish. Res. 81: 316-325. doi: 10.1016/j.fishres.2006.06.020. 
560 Tuset, V.M., Lombarte, A., and Assis, C.A. 2008. Otolith atlas for the western Mediterranean, north and central eastern 561 Atlantic. Sci. Mar. 72S1: 7-198. doi: 10.3989/scimar.2008.72s17.

562 Tuset, V.M., Lombarte, A., González, J.A., Pertusa, J.F., and Lorente, M.J. 2003. Comparative morphology of the sagittae 563 otolith in Serranus spp. J. Fish Biol. 63: 1491-1504. doi: 10.1111/j.1095-8649.2003.00262.x.

564 Tuset, V.M., Olivar, M.P., Otero-Ferrer, J.L., López-Pérez, C., Hulley, P.A., and Lombarte, A. 2018. Morpho-functional 565 diversity in Diaphus spp. (Pisces: Myctophidae) from the central Atlantic Ocean: ecological and evolutionary 566 implications. Deep Sea Res. I 138: 46-59. doi: 10.1016/j.dsr.2018.07.0005.

567 Tuset, V.M., Imondi, R., Aguado, G., Otero-Ferrer, J.L., Santschi, L., Lombarte, A., et al. 2015. Otolith patterns of 568 rockfishes from the northeastern Pacific. J. Morphol. 276: 458-469. doi: 10.1002/jmor.20353.

569 Tuset, V.M., Otero-Ferrer, J.L., Stransky, C., Imondi, R., Orlov, A., Zhenjiang, Y., et al. 2016. Otolith shape lends support 570 to the sensory drive hypothesis in rockfishes. J. Evol. Biol. 29: 2083-2097. doi: 10.1111/jeb.12932.

571 Tuset, V.M., Lombarte, A., Bariche, M., Maynou, F., and Azzurro, E. 2020. Otolith morphological divergences of 572 successful Lessepsian fishes on the Mediterranean coastal waters. Estuar. Coast. Shelf Sci. 236: 106631. doi: $573 \quad 10.1016 / j \cdot \operatorname{ecss} .2020 .106631$.

574 Venables, W.N., and Ripley, B.D. 2002. Modern Applied Statistics with S, Fourth edition. Springer Verlag, New York. 575 doi: 10.1007/978-0-387-21706-2.

576 Vignon, M., and Morat, F. 2010. Environmental and genetic determinant of otolith shape revealed by a non-indigenous 577 tropical fish. Mar. Ecol. Prog. Ser. 411: 231-241. doi: 10.3354/meps08651.

578 Volpedo, A., and Echeverría, D.D. 2003. Ecomorphological patterns of the sagitta in fish on the continental shelf off 579 Argentine. Fish. Res. 60: 551-560. doi: 10.1016/S0165-7836(02)00170-4. a high shape similarity. J. Theor. Appl. Inf. Tech. 84: 19-23.

582 Zischke, M.T., Litherland, L., Tilyard, B.R., Stratford, N. J., Jones, E.L., and Wang, Y. 2016. Otolith morphology of four 583 mackerel species (Scomberomorus spp.) in Australia: species differentiation and prediction for fisheries monitoring and assessment. Fish. Res. 176: 39-47. doi: 10.1016/j.fishres.2015.12.003.

585 Zhang, C., Ye, Z., Panhwar, S.K., and Shen, W. 2013. Stock discrimination of the Japanese Spanish mackerel 586 (Scomberomorus niphonius) based on the otolith shape analysis in the Yellow Sea and Bohai Sea. J. Appl. Ichthyol. 29: 368-373. doi:10.1111/jai.12084. 
588

589

590

591

592

593

594

595

596

597

598

599

600

601

602

603

604

605

606

607

608

609

610

611

612 Fig. 3. Matrix correlation plot between otolith shape indices showing histogram, kernel density overlays, correlations and

613 level of statistical significance $\left({ }^{*}\right) . A R$, aspect ratio; $C I R$, circularity; $E C$, edge complexity; $E L L$, ellipticity; $F F$, formfactor;

614

615

Zhuang, L., Ye, Z., and Zhang, C. 2014. Application of otolith shape analysis to species separation in Sebastes spp. from the Bohai Sea and the Yellow Sea, northwest Pacific. Environ. Biol. Fish. 98: 547-558. doi: 10.1007/s10641-014-0286$\mathrm{Z}$.

Zuur, A. F., Ieno, E.N., and Meesters, E. 2009. A Beginner's Guide to R. Springer Verlag, New York. doi: 10.1007/978-0$387-93837-0$.

\section{Legends}

Fig. 1. Left sagittae otolith of each studied species, indicating the anatomical type. aa, triangular, Synchiropus phaeton; ba, square, Gobius cruentaus; bb, square, Odondebuenia balearica; ca, rectangular, Pomatomus saltatrix; cb, rectangular, Scomber colias; cc, rectangular, Lestidiops jayakari; da, trapezoidal, Arctozenus risso; ea, pentagonal, Epigonus telescopus; eb, pentagonal, Glossanodon leioglossus; fa; hexagonal, Evermannella balbo; ga, discoidal, Microchirus boscanion; gb, discoidal, Synaphobranchus kaupii; ha, oval, Diaphus holti; hb, oval, Mullus surmuletus; ia, inverse oval, Trachyrincus scabrus; ja, elliptic, Cataetyx alleni; jb, elliptic, Cepola macrophthalma; jc, elliptic, Dissostichus eleginoides; jd, elliptic, Stromateus fiatola; je, elliptic, Engraulis encrasicolus; jf, elliptic, Alosa fallax; jg, elliptic, Lithognathus mormyrus; ka, fusiform, Serranus cabrilla; la, oblong, Phycis physis; lb, oblong, Chelon auratus; ma, lanceolated, Trachurus picturatus; na, inverse lanceolated, Merluccius hubbsi; oa, spindle-shaped, Sphyreana sphyraena; pa, inverse spindle-shaped, Micromesistius poutassou; qa, pyriform, Vinciguerria nimbaria; ra; inverse pyriform, Mora moro; sa, bullet-shaped, Argyrosomus regius; ta, tall, Argyropelecus hemigymnus; ua, hour glass trilobulated, Macroramphosus scolopax; va, hour glass, Capros aper; vb, hour glass, Lagocephalus lagocephalus; wa, pentalobulated, Zeus faber; xa, semicircular, Lophius piscatorius; ya, irregular, Hoplostethus mediterraneus; za, cuneiform, Labrus merula; *a, kidney-shaped, Merluccius paradoxus; +a, sagitiform, Gadella maraldi.

Fig. 2. Illustration of the variability of $5^{\text {th }}$ wavelets in different otolith patterns. R, rostrum. $R E C$, rectangularity; $R O$, roundness. 
616 Fig. 4. Violin plots for sensitivity $(a)$ and precision $(b)$ of different algorithms of classification applied to fish otoliths for 617 the identification of species using shape indices $\left(_{s}\right)$ and wavelets $\left({ }_{w}\right)$. ANN, artificial neuronal networks; LDA, linear 618 discriminant analysis; KNN, K-nearest neighbours; RF, random forest; SVM, support vector machine.

619

620 Fig. 5. Examples where otolith shape indices are not representative of the inter- $(a)$ and intra-specific $(b)$ variability. 


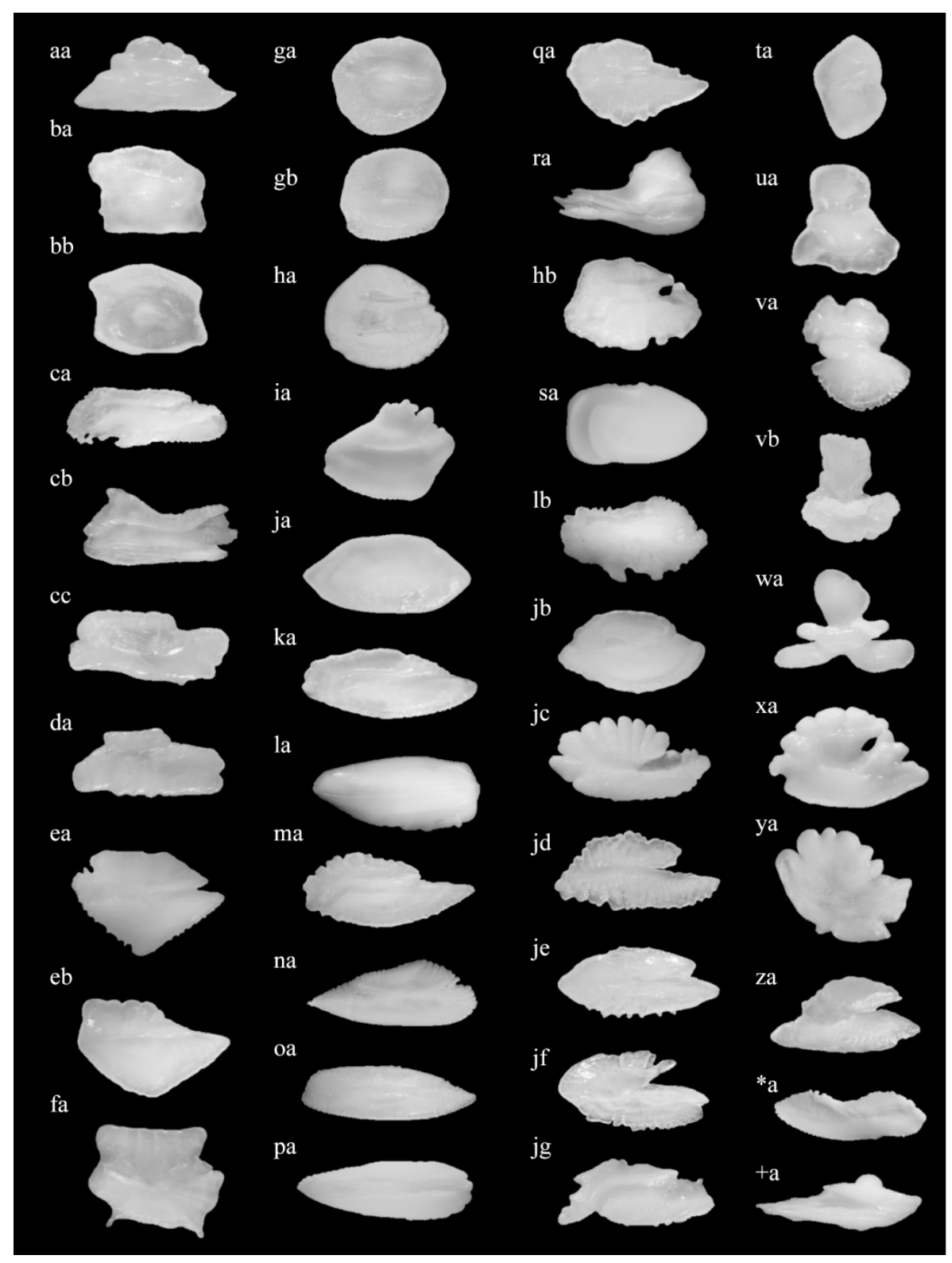



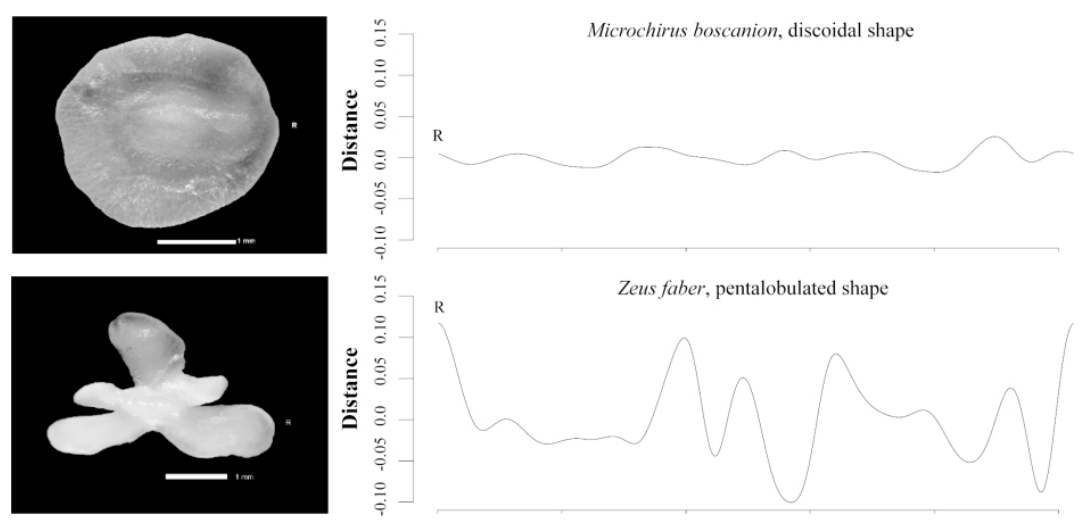

Zeus faber, pentalobulated shape

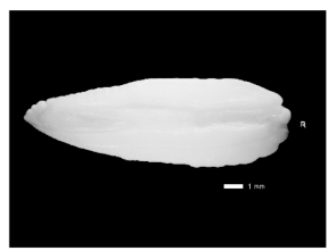

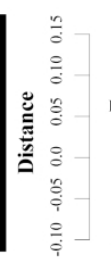
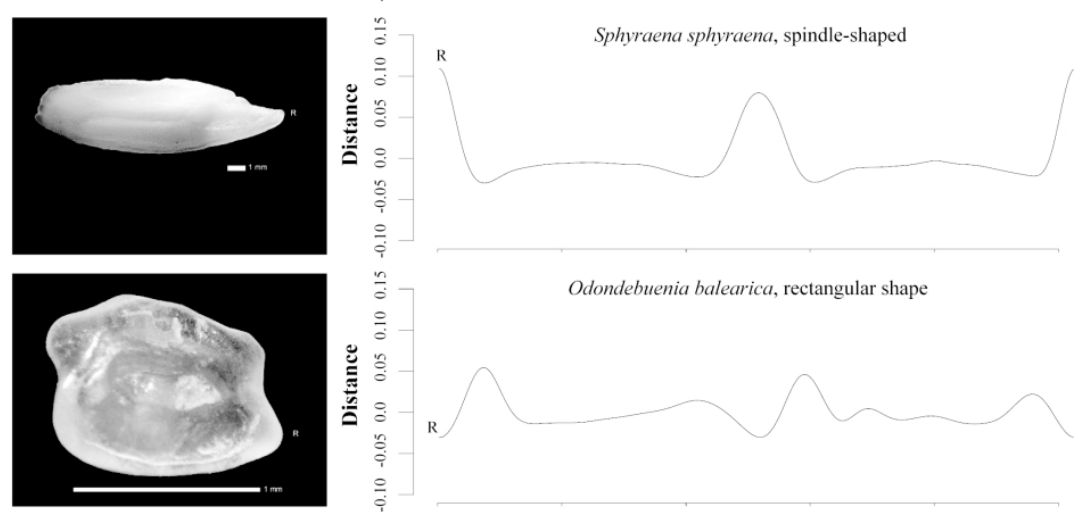

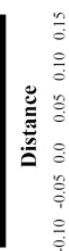
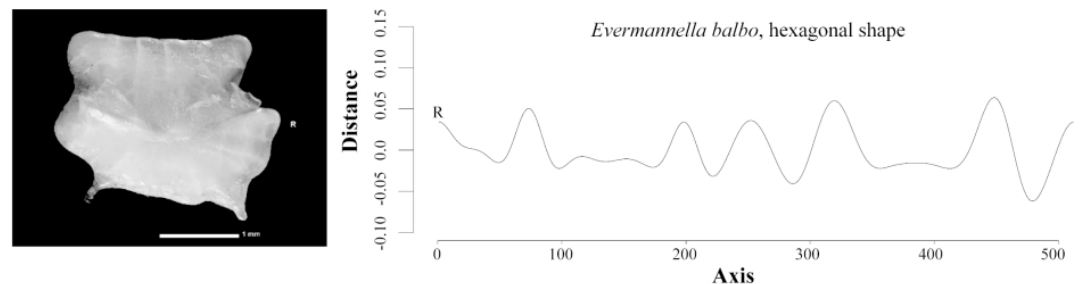


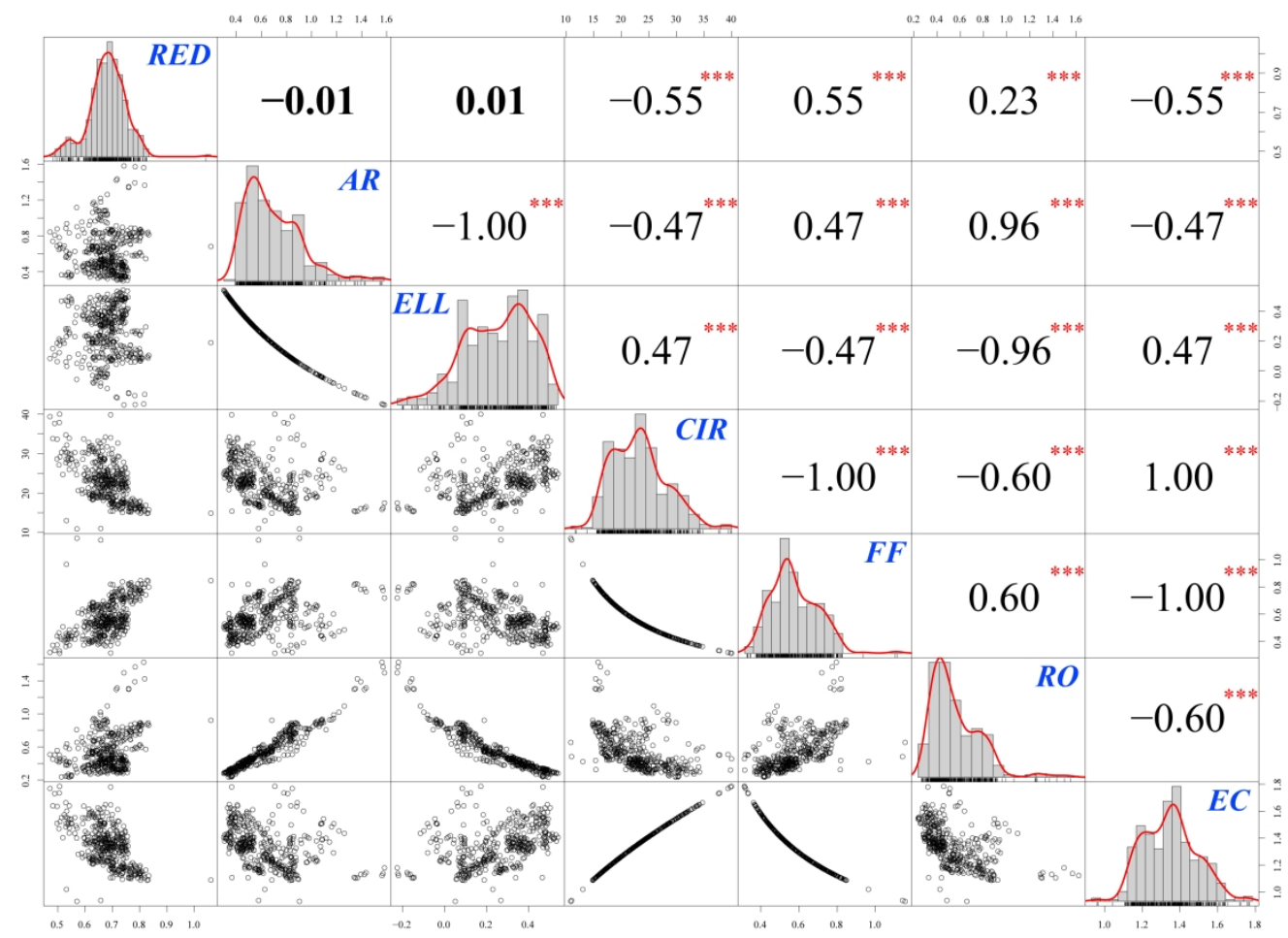



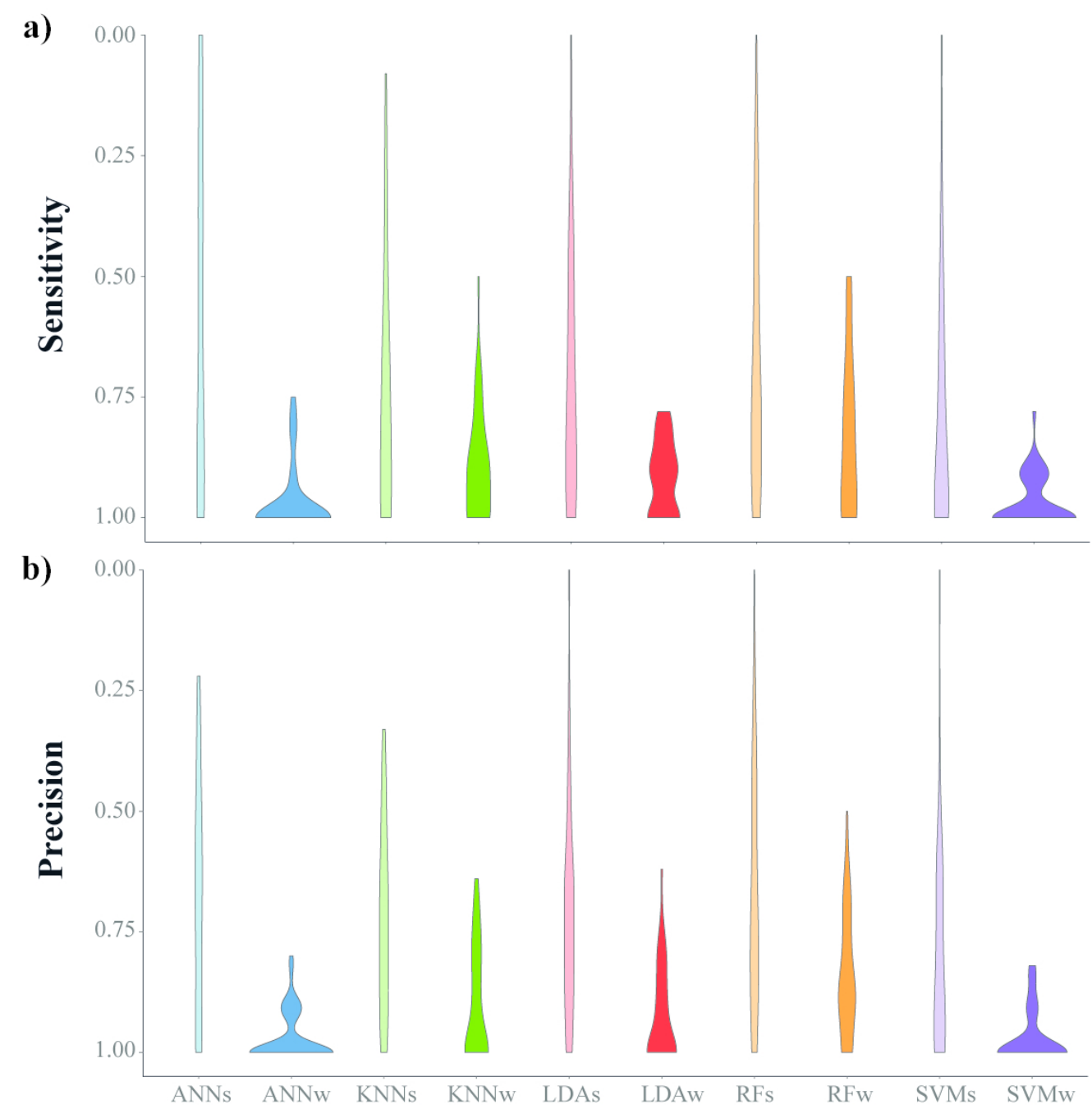

\section{Classifier}




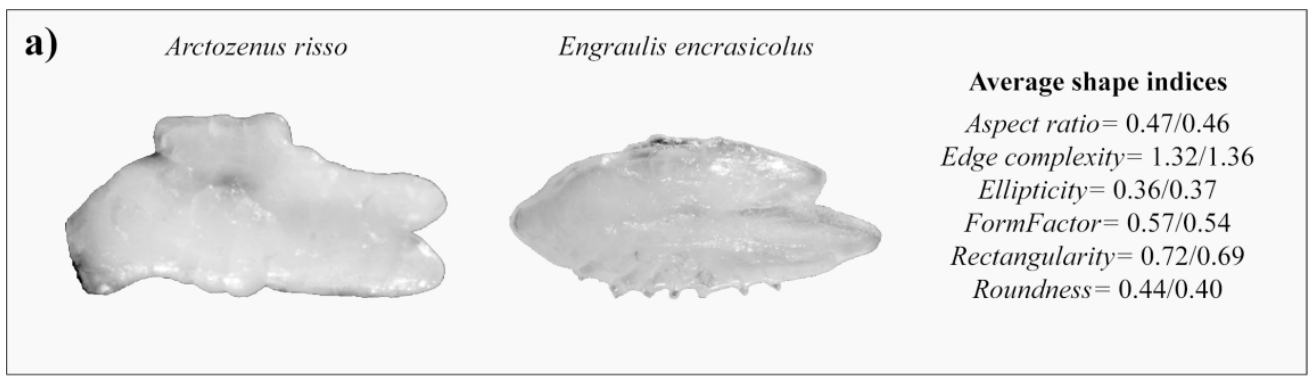

b) Synaphobranchus kaupii
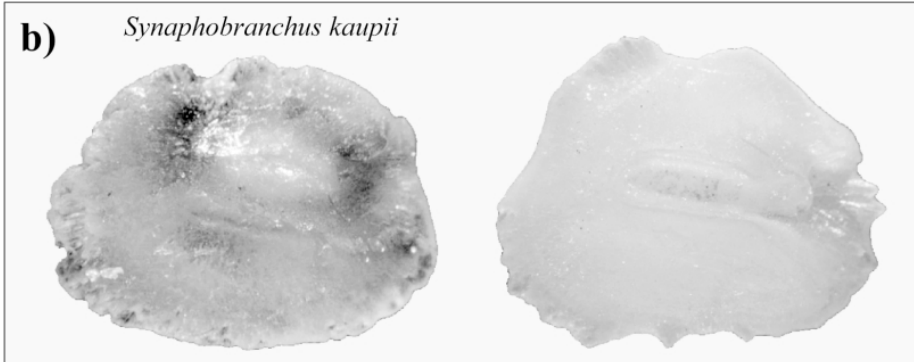

Shape indices Aspect ratio $=0.76 / 0.80$ Circularity $=17.50 / 17.21$ Ellipticity $=0.11 / 0.11$ FormFactor $=0.72 / 0.73$ Rectangularity $=0.74 / 0.77$ Roundness $=0.75 / 0.74$ Fish length $=220 / 660 \mathrm{~cm} \mathrm{TL}$ 
Table 1. Taxonomic groups (Nelson et al. 2016), species, number of specimens by species and description of the general shape of otolith, including the most remarckable traits in otolith contourn according to Tuset et al (2008).

\begin{tabular}{|c|c|c|c|c|c|c|}
\hline Order & Family & species & Acronym & Number & General shape & local traits of the contourn \\
\hline Anguilliformes & Synaphobranchidae & Synaphobranchus kaupii & Skau & 12 & Discoidal to square & margin with small irregularities \\
\hline \multirow[t]{2}{*}{ Clupeiformes } & Engraulidae & Engraulis encrasicolus & Eecn & 11 & Elliptic & ventral margin serrated \\
\hline & Clupeidae & Alosa fallax & Afal & 7 & Elliptic & antero-dorsal margin with deep identations \\
\hline Argentiniformes & Argentinidae & Glossanodon leiglossus & Glei & 11 & Pentagonal & prolongated rostrum \\
\hline \multirow[t]{2}{*}{ Stomiiformes } & Phosichthyidae & Vinciguerria nimbaria & Vnim & 8 & Elliptic to pyriform & rostrom well developed \\
\hline & Sternptychidae & Argyropelecus hemigymnus & Ahem & 9 & Tall & entire margins \\
\hline \multirow[t]{3}{*}{ Aulopiformes } & Paralepididae & Arctozenus risso & Aris & 12 & Trapezoidal & postrostrum developed with excisura caudalis \\
\hline & & Lestidiops jayakari & Ljay & 8 & Rectangular & deep excisura ostii with anteroventral projection \\
\hline & Evermannellidae & Evermannella balbo & Ebal & 5 & Hexagonal & two conspicuos needle shape ventral projections \\
\hline Myctophiformes & Myctophidae & Diaphus holti & Dhol & 11 & Oval & conspicuos serrated ventral margin \\
\hline Zeiformes & Zeidae & Zeus faber & $Z f a b$ & 10 & Trilobulated to pentalobulated & colliculum extensively protrunding \\
\hline \multirow[t]{7}{*}{ Gadiformes } & Trachyrincidae & Trachyrincus scabrus & Tsca & 12 & Elliptic to inverse oval & lobed shaped anterodorsal prominence \\
\hline & Gadidae & Micromesistius poutassou & Мрои & 12 & Inverse spindle-shaped & lobed to entire margins \\
\hline & & Phycis phycis & Pphy & 10 & Oblong & lobed to entire margins \\
\hline & Merlucciidae & Merluccius hubbsi & Mhub & 12 & Inverse lanceolated & identations in dorso-posterior margin \\
\hline & & Merluccius paradoxus & Mpar & 9 & Oblong to kidney-shaped & lobulated margins \\
\hline & Moridae & Mora moro & Mmor & 12 & Inverse pyriform & anterodorsal prominence \\
\hline & Moridae & Gadella maraldi & Gmar & 9 & Sagitiform & dorsal dome and elongated postrostrum \\
\hline Trachichthyiformes & Trachichthyidae & Hoplostethus mediterraneus & Hmed & 11 & Irregular & deep identations in dorsal margin \\
\hline Ophidiiformes & Bythitidae & Cataetyx alleni & Call & 9 & Elliptic & entire margins \\
\hline \multirow[t]{2}{*}{ Gobiiformes } & Gobiidae & Gobius cruentatus & Gcru & 11 & Square to rectangular & postero-dorsal development \\
\hline & & Odondebuenia balearica & Obal & 9 & Rectangular & entire margins \\
\hline Mugiliformes & Mugilidae & Chelon auratus & Caur & 12 & Rectangular to oblong & deep and large identations in the ventral margin \\
\hline Istiophoriformes & Sphyraenidae & Sphyraena sphyraena & Ssph & 9 & Spindle-shaped & notch in excisura ostii \\
\hline Carangiformes & Carangidae & Trachurus picturatus & Tpic & 12 & Lanceolated & crenated to lobulated margins \\
\hline
\end{tabular}




\begin{tabular}{|c|c|c|c|c|c|c|}
\hline Pleuronectidormes & Soleidae & Microchirus boscanion & Mbos & 7 & Discoidal to elliptic & entire margins \\
\hline Syngnathiformes & Macroramphosidae & Macroramphosus scolopax & Msco & 9 & Hour-glass trilobulated & pointed triangular-shape postrostrum \\
\hline Callionymiformes & Callionymidae & Synchiropus phaeton & Spha & 8 & Triangular & dorsal margin lobed with identations \\
\hline \multirow[t]{2}{*}{ Scombriformes } & Scombridae & Scomber colias & Scol & 12 & Rectangular & dorsal concavity \\
\hline & Stromateidae & Stromateus fiatola & Sfia & 8 & Elliptic & notch in excisura ostii \\
\hline Labriformes & Labridae & Labrus merula & Lmer & 10 & Cuneiform & deep angled notch in excisura ostii \\
\hline \multirow[t]{6}{*}{ Perciformes } & Serranidae & Serranus cabrilla & Scab & 10 & Fusiform & prominent rostrum and excisura ostii \\
\hline & Pomatomidae & Pomatomus saltatrix & Psal & 12 & Rectangular & deep and irregular identations in ventral margin \\
\hline & Epigonidae & Epigonus telescopus & Etel & 9 & Pentagonal to rhomboidal & identations in dorsal margin \\
\hline & Mullidae & Mullus surmuletus & Msur & 12 & Oval & margins crenate to irregular \\
\hline & Cepolidae & Cepola macrophthalma & Cmac & 9 & Elliptic & moderate peaked rostrum \\
\hline & Notothenidae & Dissostichus eleginoides & Dele & 8 & Elliptic & excisura osti,irregular margins \\
\hline Acanthuriformes & Sciaenidae & Argyrosomus regius & Areg & 9 & Bullet-shaped & entire margins \\
\hline Spariformes & Sparidae & Lithognathus mormyrus & Lmor & 12 & Elliptic to oblong & postrostrum pointed with irregularities \\
\hline Caprroiformes & Caproidae & Capros aper & Cape & 12 & Hour glass & deep excisurae, ventral margin irregular \\
\hline Lophiiformes & Lophiidae & Lophius piscatorius & Lpis & 11 & Semicircular & irregular and deeply lobulated \\
\hline Tetraodontiformes & Tetraodontidae & Lagocephalus lagocephalus & Llag & 9 & Hour-glass & developed colliculum \\
\hline
\end{tabular}


Table 2. Accuracy and kappa index obtained by different classifiers using shape indices and wavelet function at 5 th scale for fish otoliths.

\begin{tabular}{rccccc}
\hline Method & \multicolumn{5}{c}{ Classifiers } \\
\hline Shape Indices & LDA & KNN & RF & SVM & ANN \\
\hline Accuracy & 0.724 & 0.736 & 0.676 & 0.796 & 0.607 \\
$95 \%$ CI & $0.678-0.766$ & $0.691-0.777$ & $0.629-0.721$ & $0.756-0.835$ & $0.559-0.654$ \\
Kappa & 0.717 & 0.729 & 0.668 & 0.793 & 0.597 \\
Wavelet & & & & \\
Accuracy & 0.914 & 0.886 & 0.826 & 0.967 & 0.967 \\
$95 \%$ CI & $0.883-0.934$ & $0.852-0.915$ & $0.787-0.861$ & $0.945-0.982$ & $0.945-0.982$ \\
Kappa & 0.912 & 0.883 & 0.822 & 0.966 & 0.966 \\
\hline Note: ANN, artificial neuronal networks; CI, confidence interval; LDA, linear discriminant analysis; KNN, $K$-nearest
\end{tabular}
neighbour; RF, random forest; SVM, support vector machine. 